Sir,

\section{Conjunctival pigmentation as an adverse effect of} latanoprost

Eye (2004) 18, 319-320. doi:10.1038/sj.eye.6700594

Latanoprost is a prostaglandin $\mathrm{F}_{2 \alpha}$ analogue recently introduced as a topical intraocular pressure-lowering agent. Latanoprost has been reported to cause changes to pigmented tissues. The most frequently reported changes are increased pigmentation of the iris ${ }^{1,2}$ and increased pigmentation and growth of eyelashes. ${ }^{3}$

Darkening of iris colour was reported in $7 \%$ of eyes treated with latanoprost for 6 months in phase III latanoprost studies in Scandinavia, the United Kingdom, and the United States. ${ }^{1}$ It was also reported in 51 out of 277 patients of the Latanoprost Study Group in the UK. ${ }^{2}$

Other local side effects include mild conjunctival hyperaemia, irritation, and a possible association with cystoid macular oedema or anterior uveitis. ${ }^{1}$ Iris cyst formation has also been reported. ${ }^{4}$ However, to the best of our knowledge, conjunctival pigmentation has not been reported as a side effect. We report a case of conjunctival pigmentation apparently related to use of topical latanoprost.

\section{Case report}

A 78-year-old male Caucasian patient was diagnosed with primary open-angle glaucoma of his left eye. His past history included an uneventful phacoemulsification and lens implant of the right eye, and biopsy-proven temporal arteritis treated with oral steroids, which resulted in steroid-induced noninsulin-dependent diabetes mellitus. He was started on a topical b-blocker to the left eye but, after he complained of shortness of breath, this was stopped and he was started on guttae latanoprost nocté to the left eye. After 15 months, an area of patchy pigmentation measuring $4 \times 2 \times 2 \mathrm{~mm}$ was noted in the medial forniceal conjunctiva of the left eye involving the plica semilunaris (Figure 1). This area had been noticed by the patient and was causing him some irritation but no visual symptoms. Latanoprost was discontinued and replaced with brimonidine. A month later, the patient underwent an excision biopsy of the lesion in the nasal conjunctiva, combined with a left phacoemulsification and lens implant. The biopsy was sent for analysis to the Institute of Ophthalmology in London. The conjunctival specimen was goblet cell-rich with a faint dusting of pigment within the epithelium. Occasional melanocytes were seen. The pigmentation was more obvious in the immediately subjacent stroma, and there was no cellular atypia. It was concluded that the appearances were those of increased epithelial pigmentation that was not related to melanocytic hyperplasia or atypia, and that it was entirely feasible that this pigmentation was a consequence of treatment with topical latanoprost.

\section{Comment}

The mechanism by which latanoprost may cause conjunctival pigmentation is open to debate. It is believed that latanoprost-induced iris pigmentation results from elevated tyrosinase activity and melanin production but not from increased cell division. ${ }^{5}$ The underlying aetiology may be an increase in the transcription of the tyrosinase gene causing increased melanogenesis in the iridial melanocytes. Increased tyrosinase gene transcription has been found in iridial pigment epithelium and in the melanocytes of the anterior choroid. ${ }^{6}$

Furthermore, in vitro studies have shown that adding alpha-methyl- $p$-tyrosine, a tyrosinase inhibitor, completely prevented latanoprost-induced stimulation of melanin production in uveal melanocytes. ${ }^{7}$

We speculate that mechanisms of latanoprost-induced pigmentation proposed in these tissues may also be responsible for the conjunctival pigmentation seen in this case report.

It could be argued that the lesion described has a different aetiology but, if so, a suitable differential diagnosis has to be put forward. A literature search reveals a great deal of controversy and debate about the classification of conjunctival melanoses. ${ }^{8,9}$ Liesegang $^{8}$ classifies melanocytic pigmentary conjunctival lesions into congenital melanosis, nevi, acquired melanosis, and conjunctival melanoma.

Within these categories, the only two lesions that may fit the lesion described above, based on clinical and histological grounds, are one of the congenital melanoses (specifically 'benign epithelial melanosis of the conjunctiva') and one of the acquired melanoses (specifically 'primary acquired melanosis').

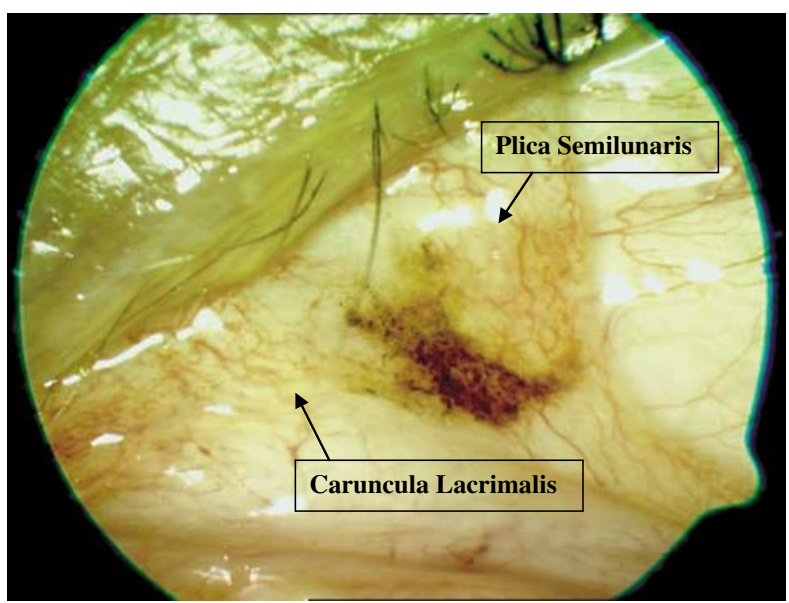

Figure 1 Pigmented lesion in the medial fornix of the left eye. 
Benign epithelial melanosis (also known as 'complexion-associated melanosis') is an unlikely candidate for our lesion because it has a predilection for dark-complected persons (affecting only 5\% of Caucasians ${ }^{9}$ ), and is usually congenital, bilateral, and located at the limbus. ${ }^{8}$

This leaves primary acquired melanosis (PAM) as a possible differential for our lesion. PAM has a predilection for middle aged to elderly Caucasians and is unilateral. PAM is characterised by poorly circumscribed, chocolate or golden-brown lesions that can occur anywhere in the conjunctiva, but is most common at the limbus and epibulbar interpalpebral region. ${ }^{8}$ PAM is classified histologically according to the presence or absence of cytological atypia. Typically, PAM without atypia (stage IA) is characterised by an increased number of melanocytes with or without hyperpigmentation. PAM without atypia may also display hyperpigmentation only, without melanocytic hyperplasia ${ }^{8}$ and this could be a differential for our lesion.

The incidence of PAM is subject to debate. Seregard et $a l^{10}$ reported that PAM occurred in $6.8 \%$ of Swedes. Gloor ${ }^{11}$ studied 200 consecutive patients attending a corneal and external diseases practice and found a prevalence of PAM of $36 \%$ among Caucasians of European ancestry with $76 \%$ limbal location and a median lesion size of $1 \mathrm{~mm}^{2}$. However, the authors conceded that many of the lesions might have been entities other than PAM. Both studies were based on clinical grounds alone and there was a higher incidence of melanosis when the subject had a darker complexion. PAM is usually larger than $6 \mathrm{~mm}$ in diameter and would not occur more frequently in individuals with darker complexions. ${ }^{9}$ Grossniklaus et al ${ }^{12}$ reviewed 2455 conjunctival lesions in adults over a 61-year period and classified them histopathologically. They found pigmented lesions in 317 patients (12.9\%) and of these only $21(0.855 \%$ of the total) were a result of acquired melanosis. Acquired melanosis was more common in women (15 patients) than men (six patients). Thus, PAM without atypia appears to be uncommon, even in white patients and is even less common in men. Although it is possible that our lesion could be PAM without atypia, factors against this include low prevalence, male patient, nonlimbal location, relatively small lesion size, and no melanocyte hyperplasia (which is the less typical form of PAM without atypia). Taking this together and given that the lesion appeared 15 months after commencing latanoprost, it would seem an unlikely coincidence for the lesion to have been PAM without atypia.

It is not clear why conjunctival pigmentation as a consequence of latanoprost has not been reported more widely, but we hope that this report will draw attention to the potential problem and promote examination of the conjunctiva in patients on topical latanoprost.

\section{Acknowledgement}

We acknowledge Professor PJ Luthert of Department of Pathology, Institute of Ophthalmology, London, UK.

\section{References}

1 Alm A, Camras CB, Watson PG. Phase III latanoprost studies in Scadinavia, the United Kingdom and the United States. Surv Ophthalmol 1997; 41 (Suppl 2): S105-S110.

2 Watson PG. Latanoprost. Two years experience of its use in the United Kingdom. Latanoprost Study Group. Ophthalmology 1998; 105(1): 82-87.

3 Johnstone MA. Hypertrichosis and increased pigmentation of eyelashes and adjacent hair in the region of the ipsilateral eyelids of patients treated with unilateral topical latanoprost. Am J Ophthalmol 1997; 124(4): 544-547.

4 Krohn J, Hove VK. Iris cyst associated with topical administration of latanoprost. Am J Ophthalmol 1999; 127(1): 91-93.

5 Dutkiewicz R, Albert DM, Levin LA. Effects of latanoprost on tyrosinase activity and mitotic index of cultured melanoma lines. Exp Eye Res 2000; 70(5): 563-569.

6 Stjernschantz J, Ocklind A, Wentzel P, Lake S, Hu DN. Latanoprost-induced increase of tyrosinase transcription in iridial melanocytes. Acta Ophthalmol Scand 2000; 78(6): 618-622.

7 Drago F, Marino A, La Manna C. Alpha-Methyl-p-tyrosine inhibits latanoprost-induced melanogenesis in vitro. Exp Eye Res 1999; 68: 85-90.

8 Liesegang TJ. Pigmented conjunctival and scleral lesions. Mayo Clin Proc 1994; 69: 151-161.

9 McLean IW. Differential diagnosis of the conjunctival melanoses. Ann Diagn Pathol 1998; 2: 264-270.

10 Seregard S, af Trampe E, Mansson-Brahme E, Kock E, Bergenmar M, Ringborg U. Prevalence of primary acquired melanosis and nevi of the conjunctiva and uvea in the dysplastic nevus syndrome. A case control study. Ophthalmology 1995; 102: 1524-1529.

11 Gloor P, Alexandrakis G. Clinical characterization of primary acquired melanosis. Invest Ophthalmol Vis Sci 1995; 36: 1721-1729.

12 Grossniklaus HE, Green WR, Luckenbach M, Chan CC. Conjunctival lesions in adults. Cornea 1987; 6(2): 78-116.

\section{AH Moosavi, MM Sarhan and T Niyadurupola}

West Sussex Eye Unit, Worthing and

St Richard's Hospitals, Lyndhurst road

Worthing, West Sussex BN11 2DH, UK

Correspondence: AH Moosavi

77 Lyndhurst Road, Worthing

West Sussex BN11 2DL, UK

Tel: +44 7801434188

E-mail: amoosavi@aol.com

None of the authors have any proprietary interest 